http://jmscr.igmpublication.org/home/ ISSN (e)-2347-176x ISSN (p) 2455-0450 crossref DOI: https://dx.doi.org/10.18535/jmscr/v8i3.98

\author{
Journal Of Medical Science And Clinical Research

\title{
Study of Lipid Profile in Non Diabetic CKD Patients
}

\author{
Authors \\ Asso Prof. Dr Malati Murmu, Asst Prof. Dr Pravas Sahu, \\ Asst Prof. Dr Manoranjan Naik, Dr Om Prakash Nayak \\ *Corresponding Author \\ Dr Soumya Ranjan Patra
}

\begin{abstract}
Background: Chronic Kidney Disease (CKD) is a worldwide health problem and one of the major health burden in developing countries like India. Dyslipidemia due to alteration in lipoprotein metabolism was considered as a complication of end stage renal disease (ESRD) but these changes can be present in early stages of CKD. Over the last decade it is established that Cardio-Vascular Disease is the major cause of mortality with mild to moderate and ESRD. The present study focused on finding an approximate prevalence of dyslipidemia,type of alteration in lipid fractions in non diabetic CKD populations and the association with staging.

Methods: The study was conducted in VIMSAR, Burla during NOV 2017 to OCT 2019 with an objective to study the lipid profile in non diabetic CKD patients. Patients with CKD admitted to Dept. of Gen. Medicine And Nephrology who had given consent for the study were the source of data. History, clinical examination with supporting biochemical and radiological evidences of 150 cases were taken for diagnosis of CKD. 75 numbers of age and sex matched healthy indivisuals were taken as control. MDRD equation was used to calculate eGFR. Staging of CKD is as per KDIGO 2012 Clinical Practice Guideline for the Evaluation and Management Of Chronic Kidney Disease.

Results: Among a total of 150 patients with mean age of $52.92 \pm 11.41$, the prevalence of dyslipidemia in CKD was found to be about $78.67 \%$. There is significant increase in serum TG with the increase in severity of the disease. Most common abnormality is fall in the serum HDL cholesterol in $59.33 \%$ of patients followed by a rise in serum triglyceride concentration $51.33 \%$ in patients suffering from CKD.

Conclusion: The high prevalence of lipid abnormalities in CKD may accelerate the progression of Cardio Vascular Disease and increase the mortality of patients. Hence it is worthwhile to early diagnose and manage accordingly to reduce morbidity and mortality.
\end{abstract}

\section{Introduction}

Chronic kidney disease (CKD) encompasses a spectrum of different patho-physiologic processes associated with abnormal kidney function and a progressive decline in Glomerular Filtration Rate (GFR)

CKD is a worldwide health problem. In the 2015 Global Burden of Disease Study, kidney disease was the 12th most common cause of death, accounting for 1.1 million deaths worldwide. Overall CKD mortality has increased by $31.7 \%$ over the last 10 years. ${ }^{1}$

The prevalence of CKD was observed to be $17.2 \%$ with $\sim 6 \%$ have CKD stage 3 or worse. ${ }^{2}$

Patients with altered renal function exhibit significant alteration in lipoprotein metabolism. ${ }^{3}$ 
Lipid abnormalities were originally considered as complications of ESRD but these changes can be present in early stages of CKD and its prevalence increases with increase in severity of disease. ${ }^{4,5}$

Dyslipidemia actively participate in the pathogenesis of serious complications such as arthero sclerotic vascular diseases. ${ }^{6}$

Over the last decade it was established that Cardio-Vascular Disease is the major cause of mortality with mild to moderate and end stage renal disease. ${ }^{6,7}$

The nature of dyslipidemia is influenced by factors like Nephrotic range proteinuria, Diabetes mellitus, Hereditary disorder of lipid metabolism, ingestion of drugs like steroid. ${ }^{4}$

According to several prospective studies the most common quantitative lipid abnormality in pre dialysis CKD patients are hyper triglyceridemia, increase concentration of triglyceride rich lipoprotein, reduced HDL-cholesterol. ${ }^{3}$

There is lack of sufficient evidence when it comes to the prevalence of dyslipidemia in patients suffering from CKD in the India and the pattern of altered lipid fractions due to the variations in the dietary habits and lifestyle differences from the western counterparts.

Indian studies on lipid abnormalities in CRF have varied from no abnormalities at all to significant abnormalities as described in western literature.

The study by Sumathi M.E, Manjunath M showed serum TGL,TC, have significantly increased in conservatively managed patients than in haemodialysis patient. ${ }^{8}$

Another study by Ganta V et al shows that, the prevalence of dyslipidemia in CKD was about $65 \%$ and it increases with increase in severity of disease. $^{5}$

The present study is undertaken to explore the pattern and prevalence of lipid abnormalities in different stages of CKD.

\section{Aims and Objectives \\ General Objective}

To find out the prevalence of dyslipidemia in non Diabetic CKD patients.

\section{Specific Objective}

To study the alteration in lipid fractions and prevalence of dyslipidemia in relation to the severity of CKD.

\section{Methodology}

Place of Study: Patients admitted in the Dept. of General Medicine and Nephrology. VIMSAR, Burla.

Period of Study: November 2017 to October 2019

Study Design: It is an analytical, Observational cross sectional study.

Study Population: Non Diabetic CKD Patients admitted in dept. of Gen Medicine and Nephrology, VIMSAR, Burla.

Sample Size: 150 number of cases and 75 numbers of heathy age and sex matched indivisuals taken as control.

Sampling Techniques: Convenience Sampling

\section{Selection Criteria}

\section{Inclusion Criteria}

1. All the patients admitted with clinical, biochemical, sonologic evidences of CKD.

2. Age:- $>14$ yrs.

\section{Exclusion Criteria}

CKD Patients with

1. Diabetes mellitus

2. Maintenance dialysis

3. Hypothyroidism and severe liver disease

4. Diagnosed dyslipidemia in medical management

5. Nephrotic range proteinuria

\section{Operational Definitions}

Diagnosis of CKD was done by clinical, biochemical and sonologic evidences of CKD

National kidney foundation defined CKD as:

1. Kidney damage for $\geq 3$ months as defined by structural or functional abnormalities of kidney, with or without decreased GFR.

Or

2. GFR $<60 \mathrm{ml} / \mathrm{min} / 1.73 \mathrm{~m} 2$ for $\geq 3$ months with or without kidney damage.

eGFR calculated by MDRD formula i,e 
Estimated GFR (mL/min per $1.73 \mathrm{~m} 2)=175 \mathrm{x}$ (S.Cr)-1.154 x (age)-0.203 (IDMS Traceable MDRD)

**Multiply by 0.742 for women multiply by 1.21 for African Americans**

Staging of CKD is based on KDIGO 2012 Clinical Practice Guideline for the Evaluation and Management Of Chronic Kidney Disease.

\section{Statistical Analysis}

Observed data were collected, compiled and analysed with appropriate statistical methods. Mean and standard deviations of lipid fractions were compared with control group by Independent Student t test. Pearsons Chi- square test is used to assess the association of different study parameters. Differences were considered statistically significant if $\mathrm{p}$ value $<0.05$.

\section{Implications of Outcome}

Diagnosis and management of lipid abnormality in early stages of CKD will decrease the morbidity and mortality due to Cardio Vascular Diseases.

Table 1 Age and Sex Distribution of Study Group

\begin{tabular}{|l|c|c|c|c|}
\hline Age & Male & Female & Total & $\begin{array}{c}\text { Percentage } \\
(\boldsymbol{\%})\end{array}$ \\
\hline $21-30$ & 2 & 2 & 4 & 2.66 \\
\hline $31-40$ & 16 & 3 & 19 & 12.67 \\
\hline $41-50$ & 18 & 25 & 43 & 28.67 \\
\hline $51-60$ & 24 & 27 & 51 & 34 \\
\hline$>60$ & 18 & 15 & 33 & 22 \\
\hline Total & $78(52 \%)$ & $72(48 \%)$ & 150 & $100 \%$ \\
\hline
\end{tabular}

In this study out of $150 \mathrm{CKD}$ patients $52 \%$ are male and $48 \%$ were female. Age of patients varies from 22 yrs to 80 yrs and majority $68.67 \%$ of the patients were in 41-60 yrs age group.

Graph 1: Age and Sex Distribution of Study Gro

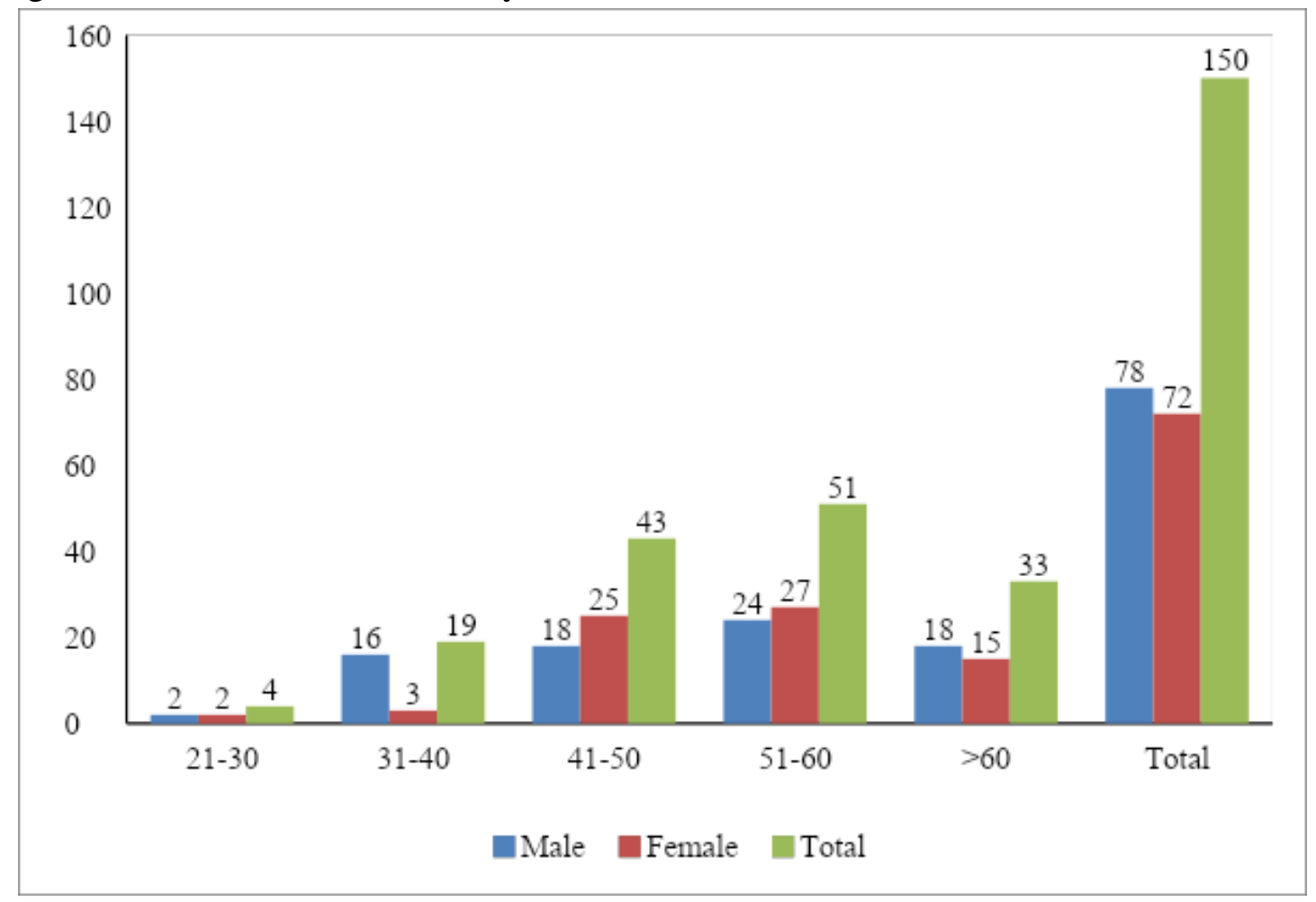

Table 2 Staging of Chronic Kidney Disease (CKD) in the study population

\begin{tabular}{|l|c|c|}
\hline CKD Stage & Number & Percentage (\%) \\
\hline Gr 3 & 20 & 13.33 \\
\hline Gr 4 & 37 & 24.67 \\
\hline Gr 5 & 93 & 62 \\
\hline Total & 150 & $100 \%$ \\
\hline
\end{tabular}




\section{JMSCR VoI||08||Issue||03||Page 567-579||March}

In the present study it was found that all the patients were suffering from Stage 3, 4, and 5 of CKD. Most of the patients were in Stage 5 CKD constituting $62 \%$ of cases. Stage 3 and 4 patients represents $13.33 \%$ and $24.67 \%$ of total study populations respectively.

Graph 2: Staging of Chronic Kidney Disease (CKD) in the study population

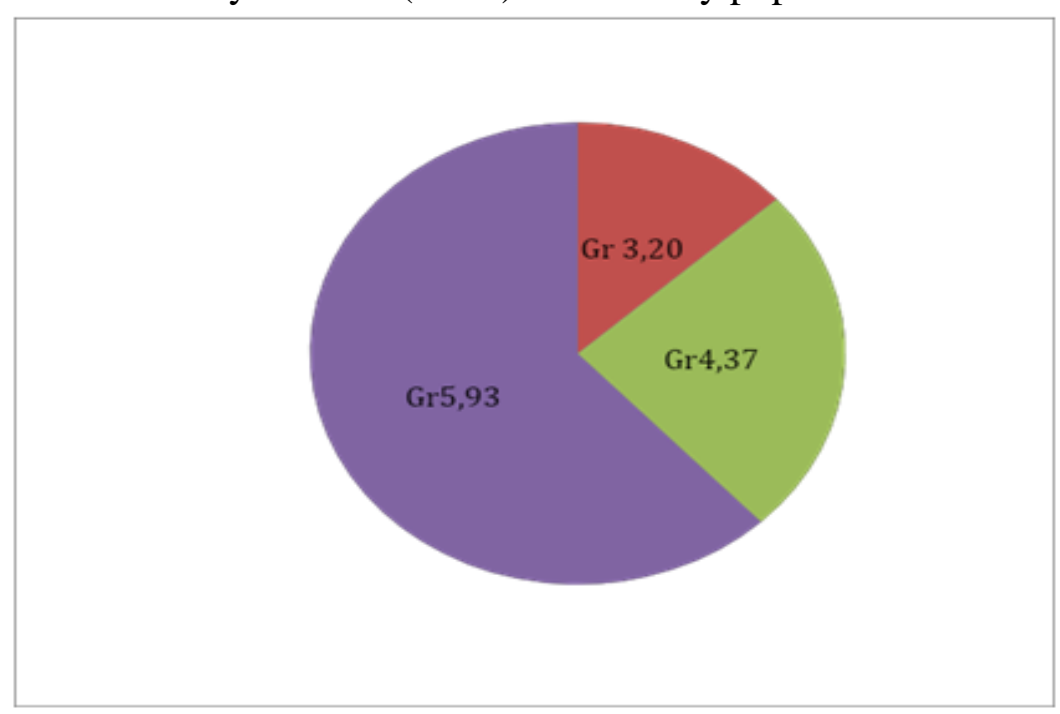

Table 3: Lipid Abnormality in Study Group

\begin{tabular}{|l|c|c|}
\hline Type of Lipid Disorder & Number Of Patient ( N=150) & Percentage (\%) \\
\hline Increased TC & 9 & 6 \\
\hline Increased TG & 77 & 51.33 \\
\hline Decreased HDL & 89 & 59.33 \\
\hline Increased LDL & 5 & 3.33 \\
\hline Total Lipid Abnormality & 118 & 78.67 \\
\hline
\end{tabular}

In our study the prevalence of dyslipidemia was found in $78.67 \%$. Most common abnormality in this study was decreased HDL (59.33\%), followed by increased $\mathrm{TG}$ in $51.33 \%$ of cases. Increased T.Ch \& LDL were seen in $6 \%$ and $3.33 \%$ of patients respectively.

Graph 3: Lipid Abnormality in Study Group

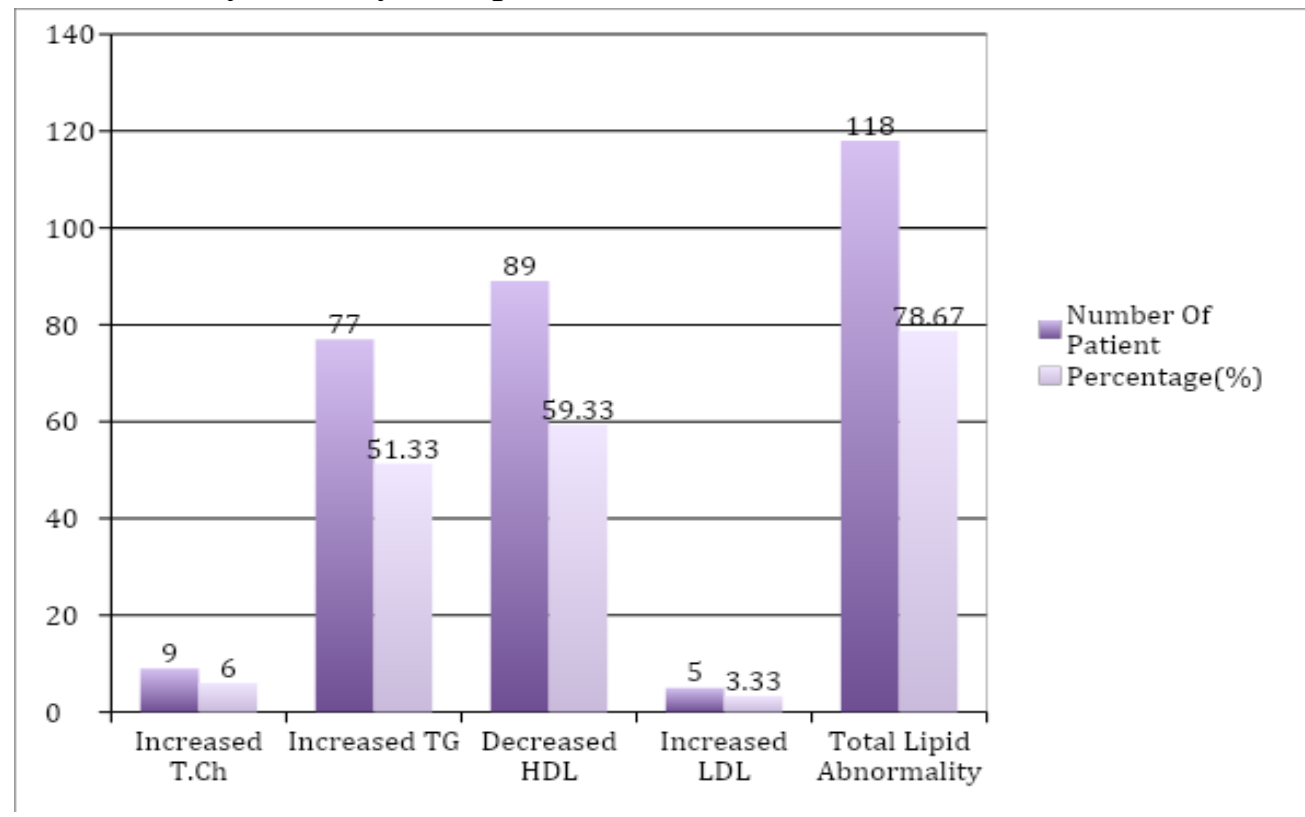


Table 4 Prevalence of Dyslipidemia Vs. Stages of CKD.

\begin{tabular}{|c|c|c|c|c|}
\hline Lipid Profile & CKD III & CKD IV & CKD V & P value/Chi \\
\hline Abnormal & $15(75 \%)$ & $27(73 \%)$ & $76(81.7 \%)$ & \multirow{3}{*}{$\begin{array}{c}\mathrm{P}=0.28 \\
\text { Chi sq= 2.49 } \\
\mathrm{df}=2\end{array}$} \\
\hline Normal & $5(25 \%)$ & $10(27 \%)$ & $17(18.3 \%)$ & \\
\hline Total & $20(100 \%)$ & $37(100 \%)$ & $93(100 \%)$ & \\
\hline
\end{tabular}

Comparing the dyslipidemia with staging of CKD, it was found that lipid abnormality in Stage III, IV and V were $75 \%, 73 \%$ and $81.7 \%$ respectively.

Graph 4: Prevalence of Dyslipidemia Vs. Stage of CKD

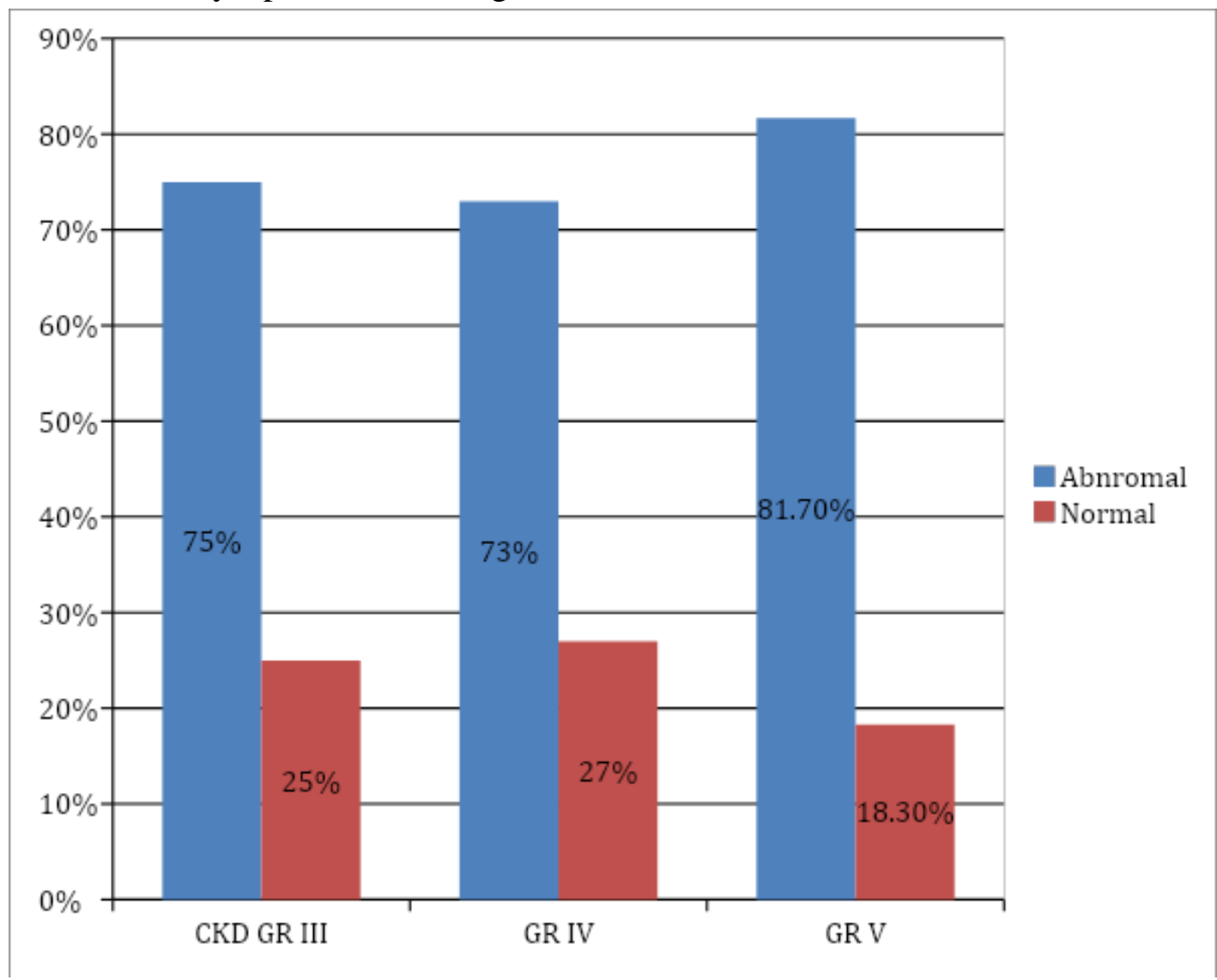

Table 5 Correlation between Lipid Fractions and Stage of CKD

\begin{tabular}{|l|c|c|c|}
\hline LIPID FRACTION & Stage III n=20 & Stage IV n= 37 & Stage V n = 93 \\
\hline$\uparrow$ TC & 1 & 3 & 5 \\
\hline$\uparrow$ TG & $9(45 \%)$ & $12(32.43 \%)$ & $56(60.21 \%)$ \\
\hline$\downarrow$ HDL & $10(50 \%)$ & $18(48.64 \%)$ & $61(65.59 \%)$ \\
\hline$\uparrow$ LDL & 0 & 2 & 3 \\
\hline
\end{tabular}

In this study decreased HDL was the most frequent abnormality which was found in $65.59 \%$ of patients in Stage V .In Stage III and Stage IV population decreased HDL was $50 \%$ \& $48.64 \%$ respectively. Increased TG found in Stage III, IV $\& \mathrm{~V}$ were $45 \%, 32.43 \%$ and $60.21 \%$ respectively. 
Graph 5: Correlation between Lipid Fractions and Stage of CKD

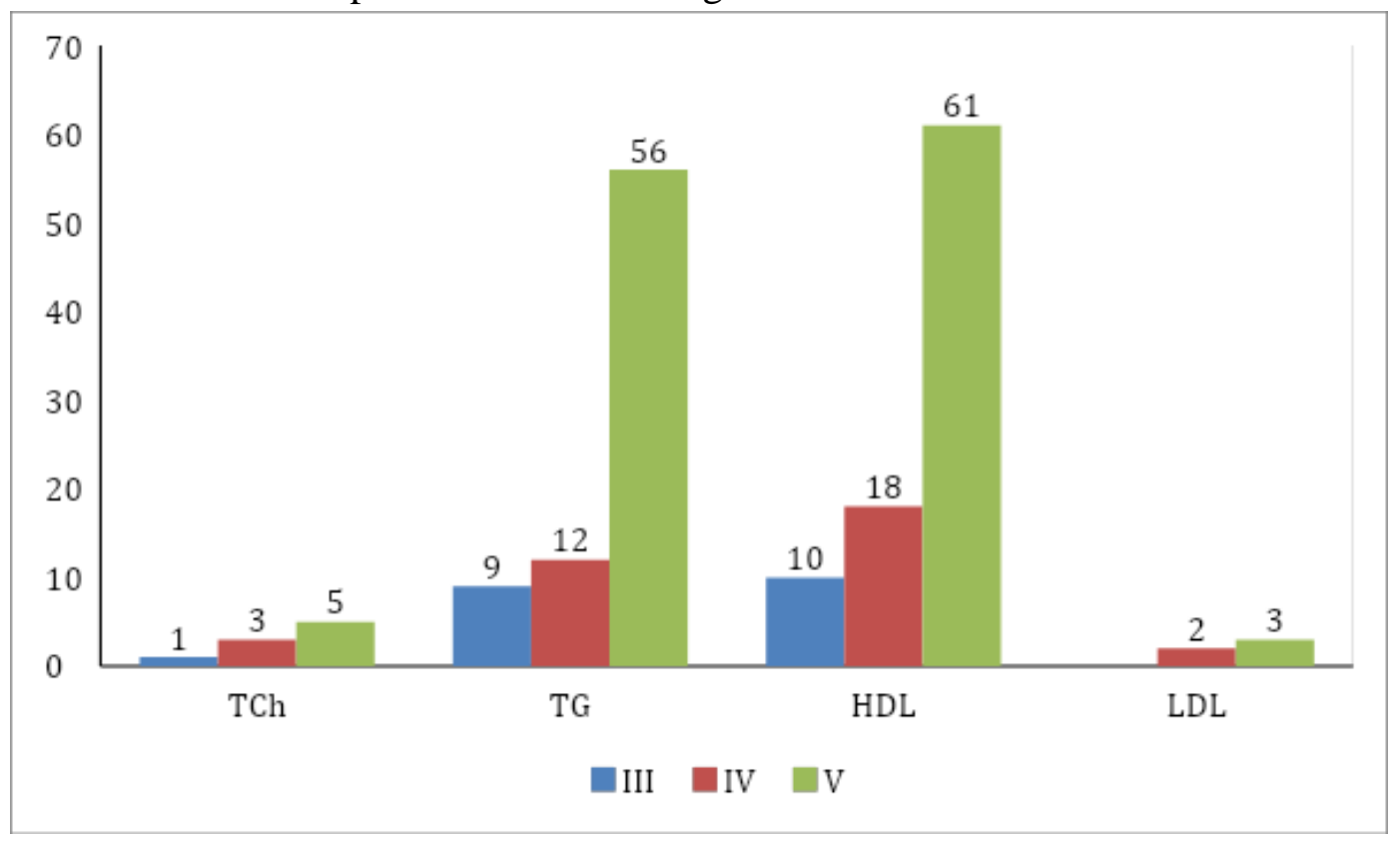

Table 6: Lipid fraction of Patients (Study Group) Vs Control

\begin{tabular}{|l|c|c|c|}
\hline LIPID FRACTION & PATIENT(n=150) & CONTROL(n=75) & $\boldsymbol{P}$ Value \\
\hline TC & $145.99 \pm 40.79$ & $143.02 \pm 30.72$ & 0.57 \\
\hline TG & $163.18 \pm 83.53$ & $101.65 \pm 20.71$ & $<0.05$ \\
\hline HDL & $32.82 \pm 14.01$ & $39.82 \pm 8.21$ & $<0.05$ \\
\hline LDL & $77.37 \pm 35.78$ & $75.14 \pm 22.22$ & 0.6 \\
\hline
\end{tabular}

Comparing the mean values of different lipid fractions we found statistically significant $(\mathrm{p}<0.05)$ difference in TG and HDL levels between study and control groups.

Graph 6: Mean Lipid fractions of Patients (Study Group) Vs Control

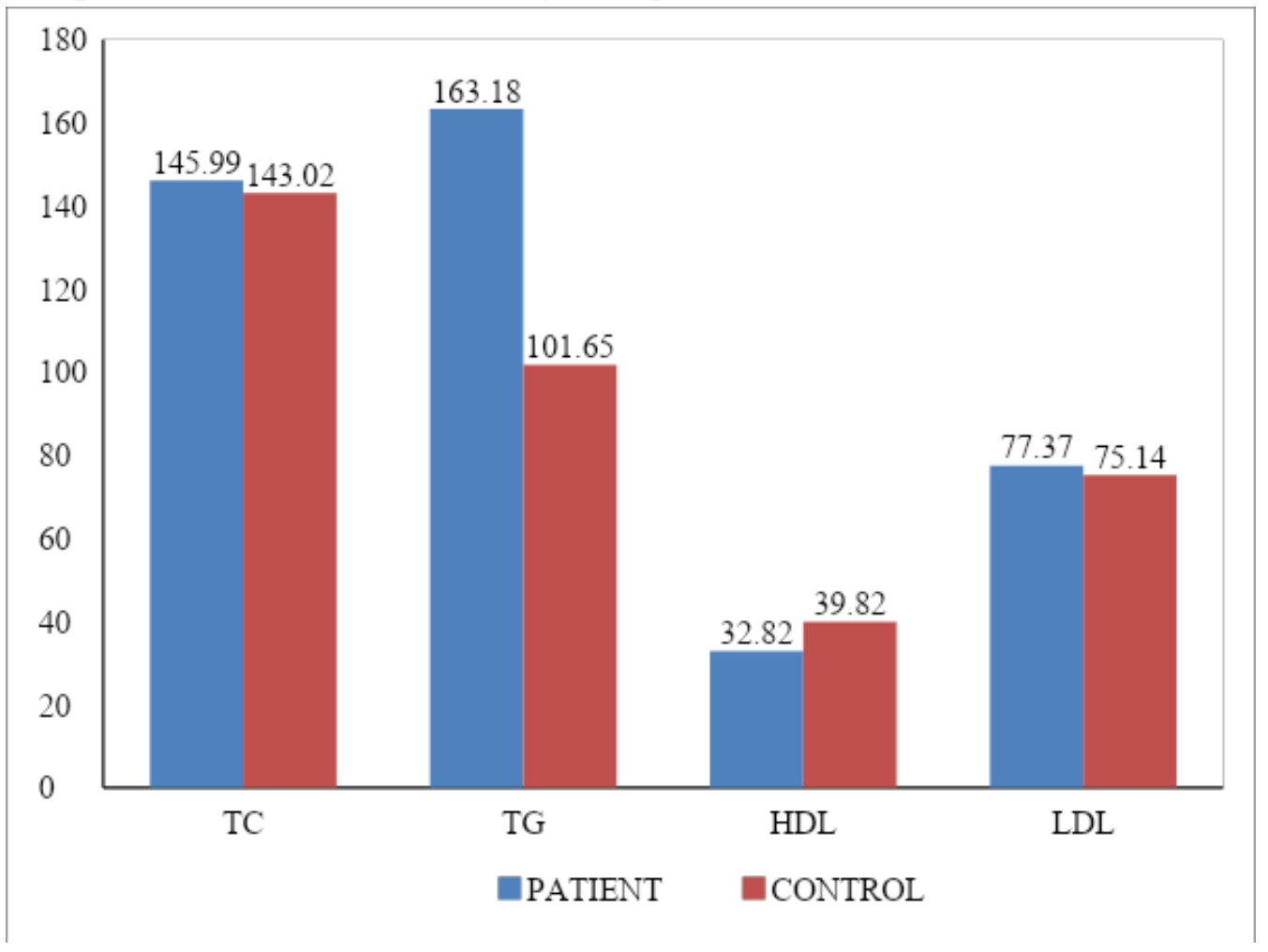




\section{JMSCR Vol||08||Issue||03||Page 567-579||March}

\section{Lipid Fractions in Relations to Stages of CKD}

Table 7 Total Cholesterol Vs Stage of CKD

\begin{tabular}{|l|c|c|c|c|}
\hline TC & Stage III $(\mathbf{n = 2 0})$ & Stage IV $(\mathbf{n}=\mathbf{3 7})$ & Stage $\mathbf{V}(\mathbf{n}=\mathbf{9 3})$ & P value \\
\hline Abnormal $(\uparrow)$ & 1 & 3 & 5 & $P=0.823$ \\
\hline Normal & 19 & 34 & 88 & Chi $\mathrm{Sq}=0.39$ \\
\hline
\end{tabular}

Total Cholesterol level in Stage III, IV and V of CKD in our study was found to be abnormal in 1 , 3 and 5 number of patients respectively. We found no significant relationship $(p=0.823)$ between TC level and stages of CKD in our study.

Graph 7: Total Cholesterol Vs Stage of CKD

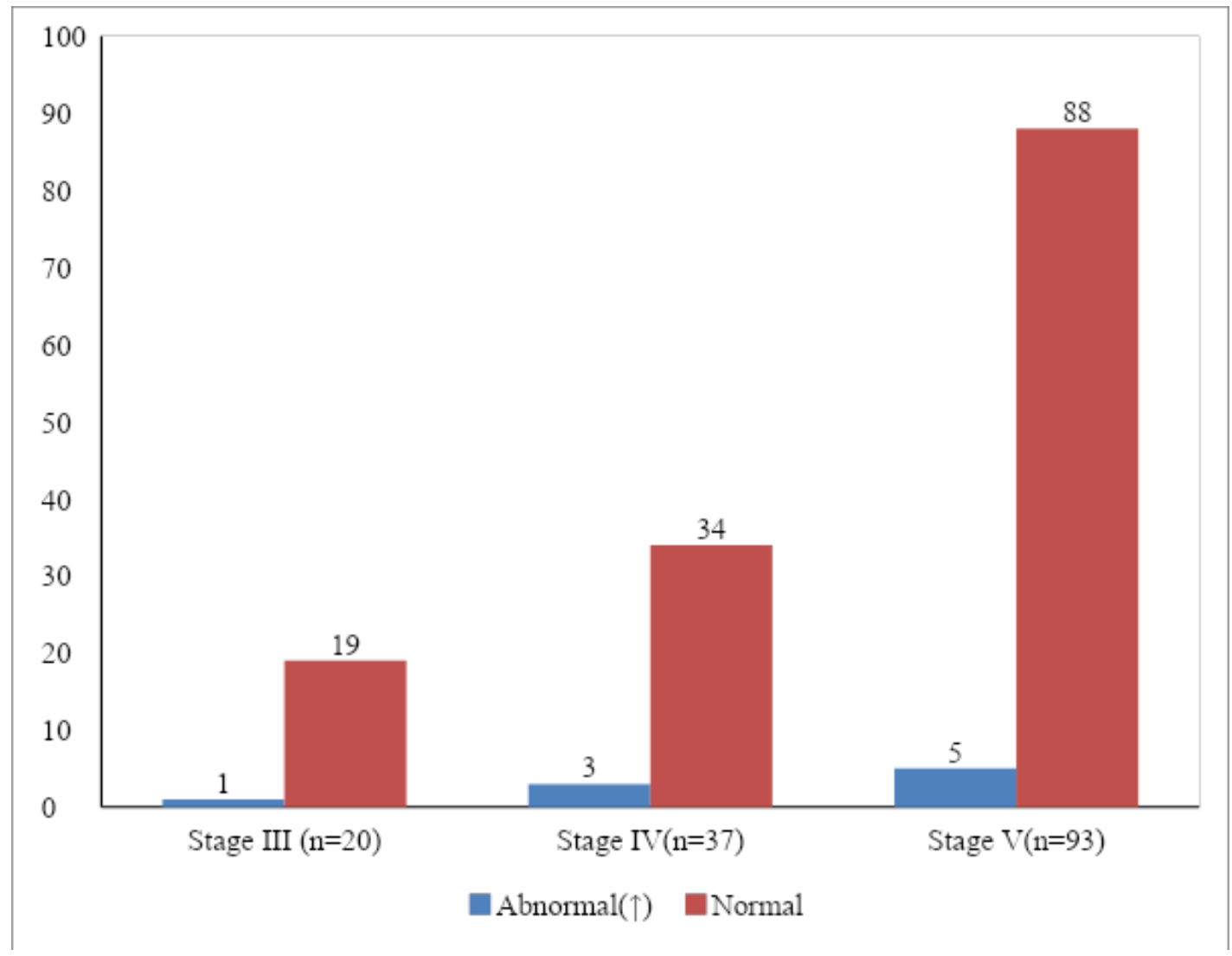

Table $-\mathbf{8}$ TG Vs Stage of CKD

\begin{tabular}{|l|c|c|c|c|}
\hline TG & Stage III $(\mathbf{n}=\mathbf{2 0})$ & Stage IV(n=37) & Stage V(n=93) & $\boldsymbol{P}$ value \\
\hline Abnormal $(\uparrow)$ & 9 & 12 & 56 & $P=0.013$ \\
\hline Normal & 11 & 25 & 37 & Chi Sq=3.98 \\
\hline
\end{tabular}

Triglyceride fraction in Stage III, IV and V of CKD in this study was found to be abnormal in 9, 12 and 56 number of patients respectively. There was statistically significant $(p=0.013)$ increase in TG level in relation to increased severity of CKD in our study. 


\section{JMSCR Vol||08||Issue||03||Page 567-579||March}

Graph 8: TG Vs Stage of CKD

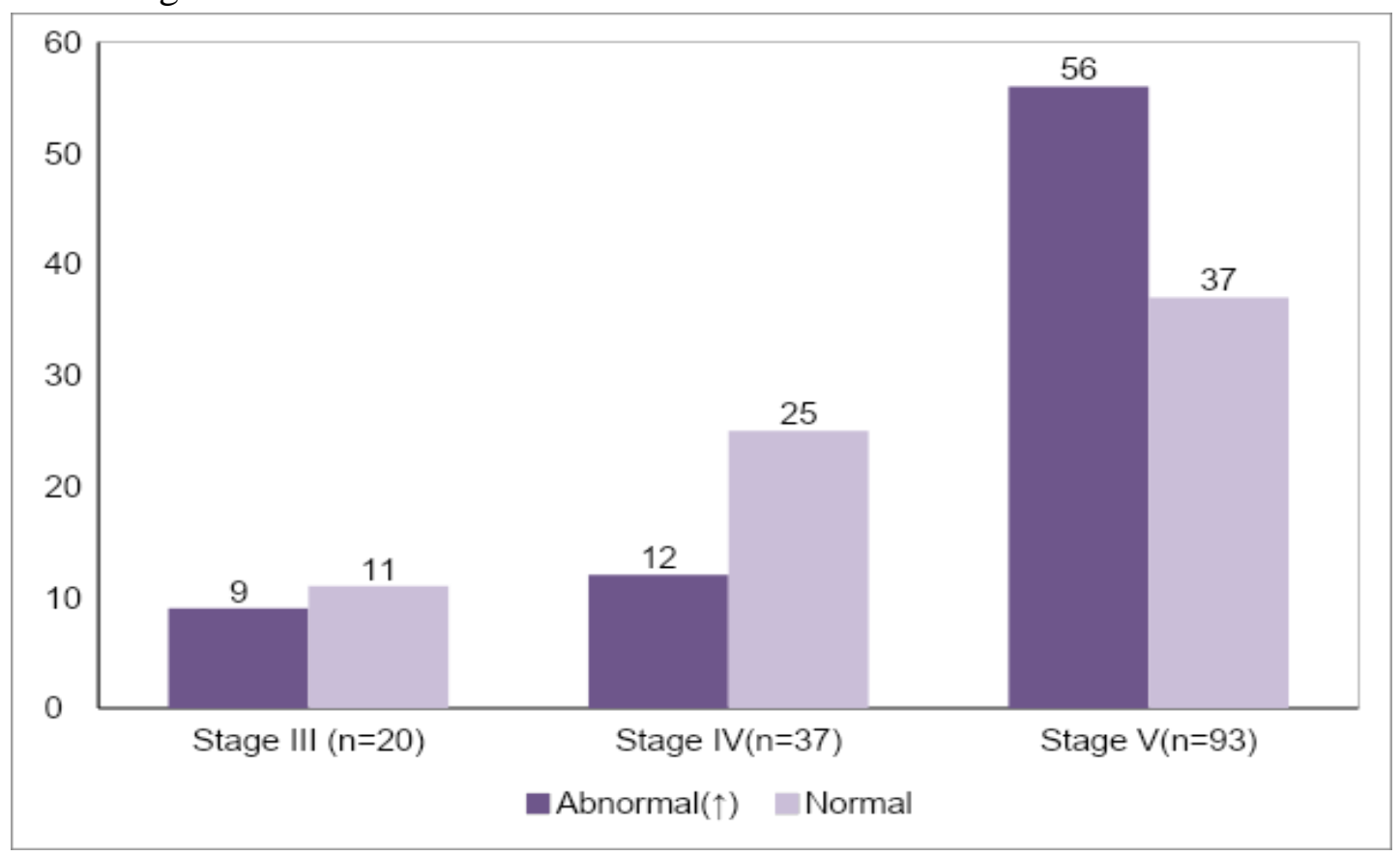

Table 9 HDL Vs Stage of CKD

\begin{tabular}{|l|c|c|c|c|}
\hline HDL & Stage III $(\mathbf{n}=\mathbf{2 0})$ & Stage IV(n=37) & Stage V(n=93) & $\boldsymbol{P}$ value \\
\hline Abnormal $(\downarrow)$ & 10 & 18 & 61 & $P=0.136$ \\
\hline Normal & 10 & 19 & 32 & Chi Sq=3.98 \\
\hline
\end{tabular}

HDL level in Stage III, IV and V of CKD in this study was found to be abnormal in 10, 18, and 61 number of patients respectively. There was no statistically significant ( $p=0.136$ ) decrease in HDL level in relation to increased severity of CKD in our study.

Graph 9: HDL Vs Stage of CKD

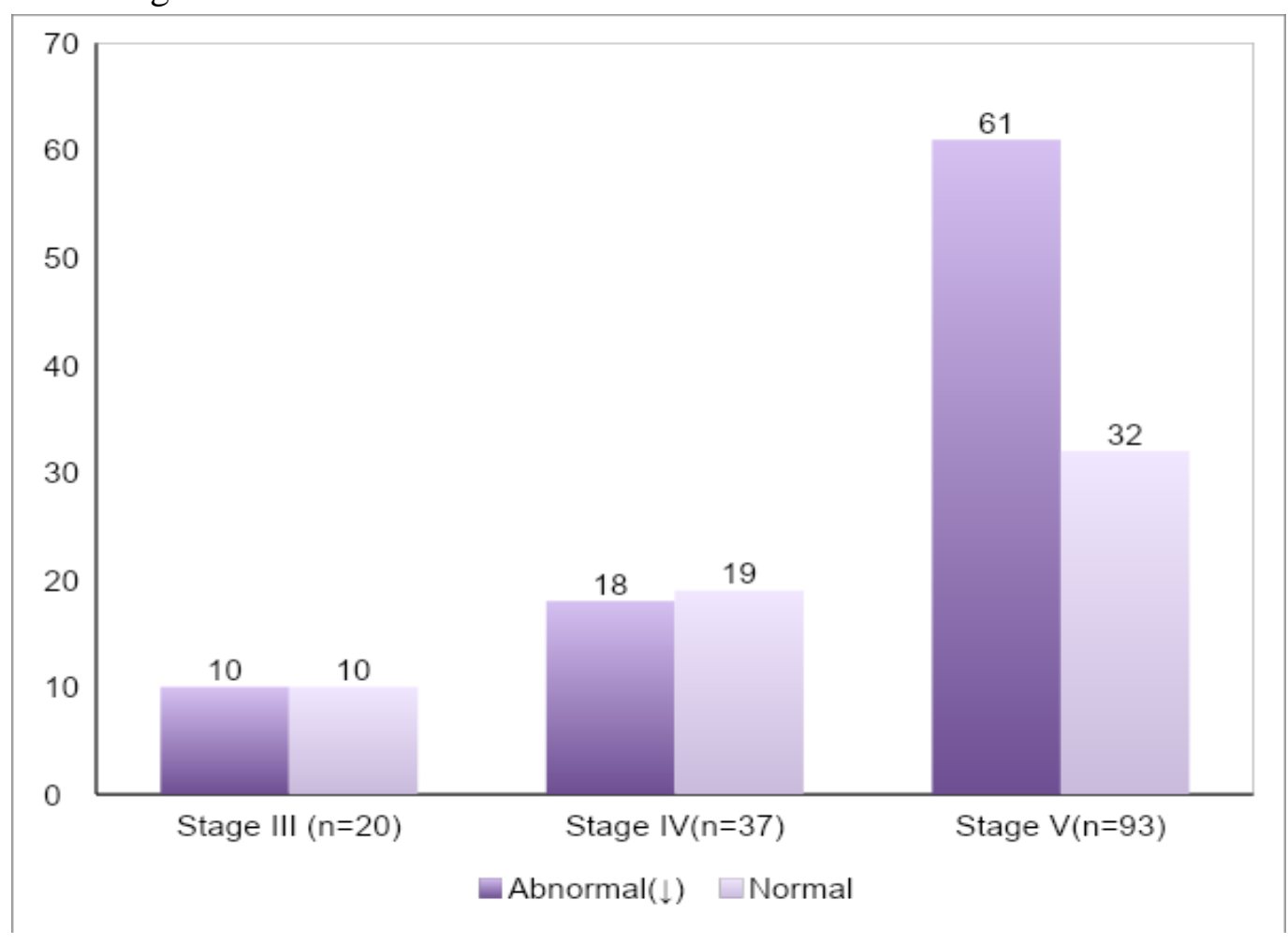


Table 10 LDL Vs Stage of CKD

\begin{tabular}{|l|c|c|c|c|}
\hline LDL & Stage III $(\mathbf{n}=\mathbf{2 0})$ & Stage IV $(\mathbf{n}=\mathbf{3 7})$ & Stage $\mathbf{V}(\mathbf{n}=\mathbf{9 3})$ & $\boldsymbol{P}$ value \\
\hline Abnormal $(\uparrow)$ & 0 & 2 & 3 & $P=0.55$ \\
\hline Normal & 20 & 35 & 90 & Chi $\mathrm{Sq}=0.34$ \\
\hline
\end{tabular}

LDL level in Stage III, IV and V of CKD in this study was found to be abnormal in 0,2 , and 3 number of patients respectively. There was no statistically significant $(\mathrm{p}=0.55)$ increase in LDL level in relation to increase severity of $\mathrm{CKD}$ in our study.

Graph 10: LDL Vs Stage of CKD

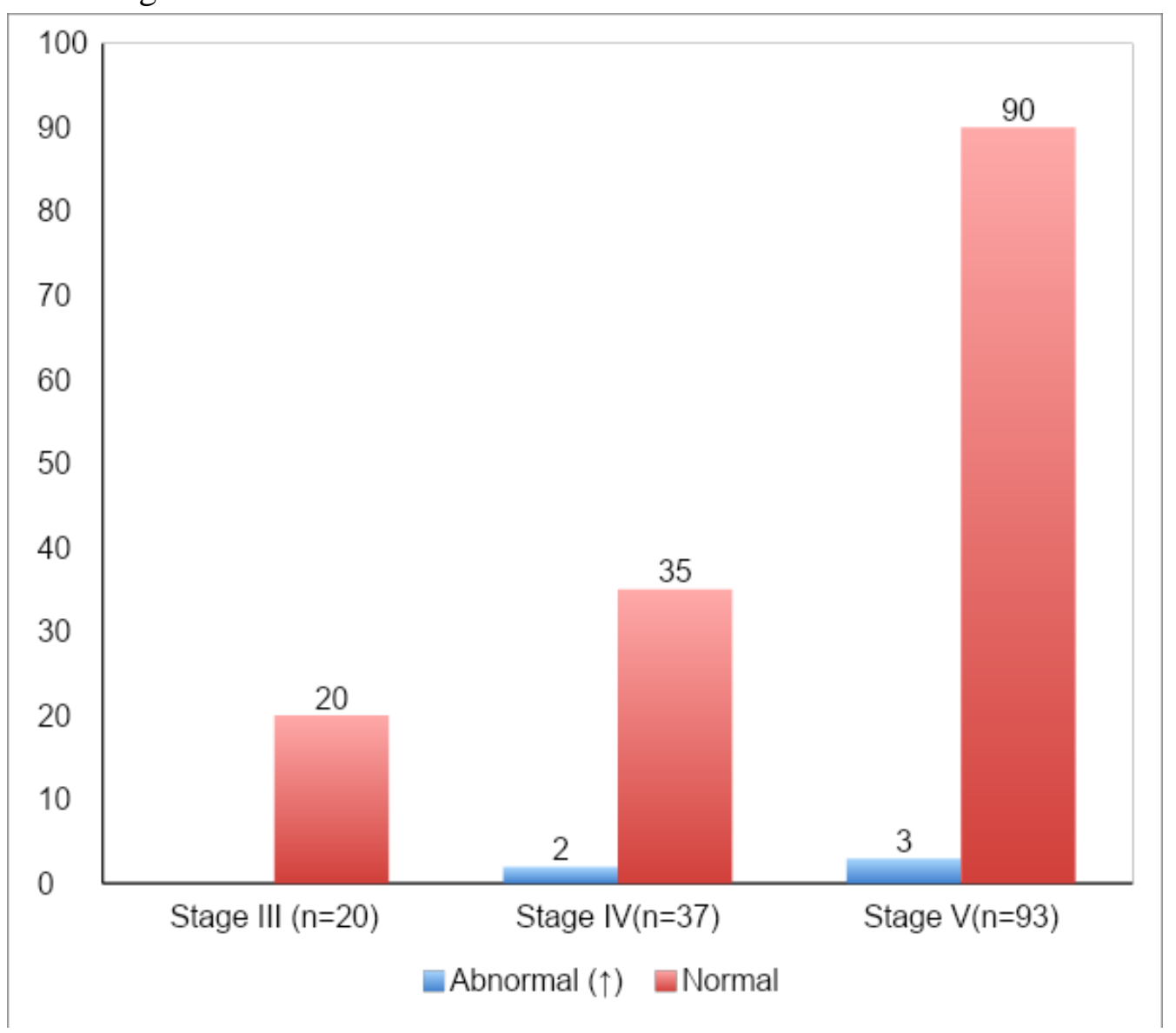

\section{Discussion}

Chronic kidney disease (CKD) results in profound lipid disorders, which stem largely from dysregulation of high-density lipoprotein (HDL) and triglyceride-rich lipoprotein metabolism. Specifically, maturation of HDL is impaired and its composition is altered in CKD.

In addition, clearance of triglyceride-rich lipoproteins and their atherogenic remnants is impaired, their composition is altered, and their plasma concentrations are elevated in CKD. Impaired maturation of HDL in CKD is primarily due to down regulation of lecithin cholesterol acyltransferase (LCAT) and, to a lesser extent, increased plasma cholesteryl ester transfer protein (CETP). Triglyceride enrichment of HDL in CKD is primarily due to hepatic lipase deficiency and elevated CETP activity.

The CKD-induced hypertriglyceridemia, abnormal composition, and impaired clearance of triglyceride-rich lipoproteins and their remnants are primarily due to down regulation of lipoprotein lipase, hepatic lipase, and the verylow-density lipoprotein receptor, as well as, upregulation of hepatic acyl-CoA cholesterol acyltransferase (ACAT). In addition, impaired HDL metabolism contributes to the disturbances of triglyceride-rich lipoprotein metabolism. These 
abnormalities are compounded by downregulation of apolipoproteins apoA-I, apoA-II, and apoC-II in CKD. Together, these abnormalities may contribute to the risk of arteriosclerotic cardiovascular disease and may adversely affect progression of renal disease and energy metabolism in CKD.

Hyperlipidemia accelerates progression of renal disease by several mechanisms. Reabsorption of fatty acids, phospholipids, and cholesterol contained in the filtered proteins by tubular epithelial cells can stimulate tubulointerstitial inflammation, foam cell formation, and tissue injury. ${ }^{14,15}$ Accumulation of lipoproteins in glomerular mesangium can promote matrix production and glomerulosclerosis. ${ }^{16-18}$ In this context, native and oxidized lipoproteins, particularly LDL, stimulate production of matrix proteins by cultured mesangial cells and promote generation of proinflammatory cytokines, which can lead to recruitment and activation of circulating and resident macrophages. ${ }^{19,20,21}$

In addition, impaired HDL-mediated reverse cholesterol transport can further contribute to tissue injury by limiting the unloading of the excess cellular cholesterol and phospholipid burden. In fact, low plasma HDL has been identified as an independent risk factor for progression of renal disease. 22,23 Moreover, hereditary LCAT deficiency, which is associated with a marked reduction in HDL cholesterol and impaired HDL-mediated reverse cholesterol transport, results in progressive renal disease. ${ }^{24}$

The present study consisted of 150 patients of non diabetic chronic kidney disease .These patients satisfied the criteria laid by the National kidney foundation kidney disease outcome quality initiatives (NKF-KDOQI) for diagnosing CKD.

\section{Age and Sex Distribution}

In this study age of the patients varies from $22 \mathrm{yrs}$ to $80 \mathrm{yrs}$ and majority $68.67 \%$ of the patients are in 41-60 yrs age group. Maximum number of CKD cases are in there 5th to 6th decades of life. Mean age of the patients in our study is $52 \pm$
11.41 and this is consistent with the observation made by Rajapurkar et al. ${ }^{11}$.In this study $52 \%$ of patients were male and $48 \%$ were female which is similar to the observation made by Agarwal SK, Dash SC et al $^{12}$ but differs from the study of Rajapurkar et al in which male to female ratio was found 2.33: 1 .

\section{Staging of Chronic Kidney Disease (CKD) in the Study Population}

In the present study it was found that all the patients were suffering from Stage 3, 4, 5 of CKD. Most of the patients were in Stage 5 i,e $62 \%$ of cases. Stage 3 and 4 patients represents $13.33 \%$ and $24.67 \%$ of total study populations respectively and none in Stage 1 and 2 Which was similar to the finding of Sathyan et al. ${ }^{13}$ Majority of the patients are in Stage 4 and 5.

\section{Dyslipidemia in CKD}

The results of this study on the lipid profile in patients with chronic kidney disease show that there are significant alteration in lipid profiles of these patients.

\section{Prevalence of Dyslipidemia}

In the study population the prevalence of dyslipidemia was found $78.67 \%$ which is consistent with the findings of Ganta $\mathrm{V}$ et al (65.5\%), P Mohanraj, G. Anbazhagan, S. Kalaivalli (74\%). Most common abnormality in this study is decreased HDL $59.33 \%$ followed by increased TG in $51.33 \%$ of cases. Increased T.Ch $\&$ LDL are seen in $6 \%$ and $3.33 \%$ of patients respectively. The prevalence of dyslipidemia in Stage III, IV and V were $75 \%, 73 \%$ and $81.7 \%$ respectively. In our study we found no significant relationship $(\mathrm{p}=0.28$, chi $\mathrm{sq}=2.49)$ between prevalence of dyslipidemia with severity of CKD but Ganta V et al have noted significant relationship. This may be due to the variation in sample size in different stages of chronic kidney disease. When individual fractions of lipid profile were compared with the stages of CKD, decreased HDL is the most frequent abnormality which was found in $65.59 \%$ of patients in Stage V .In Stage III and Stage IV population deceased HDL was 
$50 \% \& 48.64 \%$ respectively. Increased TG found in Stage III, IV \& V were $45 \%, 32.43 \%$ and $60.21 \%$ respectively. Abnormality in serum TG level was found statistically significant $(\mathrm{p}=0.013)$ in relation to severity of CKD but rest of the fractions shown no significant association.

\section{Decreased HDL Cholesterol}

Most common lipid abnormality in our study is decreased HDL levels found in 59.33\% of patients. Mean HDL in study and control group are 32.82 \pm 14.01 and 39.82 \pm 8.21 . There is statistically significant difference obtained between study population and the controls $(p<0.05)$. Similar observation has been noted by P. Mohanraj, G. Anbazhagan, S. Kalaivalli in their study but it differs from many studies by Ganta V et $\mathrm{al}^{5}$, , Gupta $\mathrm{DK}^{25}$,Das $\mathrm{BS}^{26}$ and Bagdae $\mathrm{J}^{27}$ Diana M Lee LG et al ${ }^{28}$, where hypertriglyceridemia is the most common lipid abnormality. Study of Rapoport, Aviram, showed there is no decrease in HDL concentration in chronic kidney disease patients. ${ }^{29}$ Nisha I. Parikh, Shih-Jen Hwang, Marin G. Larson noted low HDL and CKD have a synergistic effects on cardiovascular disease risk. ${ }^{30}$

Recent study by Bowen B et al, found significant association between low HDL levels and risk of incident $\mathrm{CKD}$ and $\mathrm{CKD}$ progression. ${ }^{31}$

\section{Elevated Trigycerides}

Second most frequent lipid abnormality in our study is Hypertrigyceridemia ( $\uparrow \mathrm{TG}$ ). Mean value of study and control group were $163.18 \pm 83.53$ and $101.65 \pm 20.71$ respectively. The present study demonstrates that there was a significant alteration $(p<0.05)$ in TG fractions between study population and the control group. CRF is commonly accompanied by lipid abnormality in the form of hypertriglyceridemia. This is similar to the observations made in Western studies and recent Indian studies by P. Mohanraj, G.Anbazhagan, S. Kalaivalli, ${ }^{4}$ Ganta V et al, ${ }^{5}$ Gupta DK, ${ }^{25}$ Das BS ${ }^{26}$ and Bagdae J.et al. ${ }^{27}$

\section{Total Cholesterol and LDL}

In this study the total cholesterol level was marginally elevated in $6 \%$ and LDL in $3.33 \%$ of patients. Shah et al, in their study showed no significant change in levels of total cholesterol. ${ }^{32}$ Gerald Appel et al., showed normal or decrease in LDL levels. ${ }^{33}$

Anderson et al, showed increase in LDL levels which differs from our observation. ${ }^{34}$

Chronic kidney disease in the absence of heavy proteinuria does not significantly affect gene expressions of either hydroxyl-3-methylglutarylCoA reductase (HMG-CoA reductase) which is the rate-limiting enzyme for cholesterol biosynthesis, or that of cholesterol 7a-hydroxylase which is the rate-limiting enzyme for cholesterol catabolism and conversion to bileacids. ${ }^{35}$ So CKD in the absence of heavy proteinuria does not alter hepatic LDL receptor gene expression, thereby LDL levels are not elevated.Heavy proteinuria alone or in combination with chronic renal insufficiency results in acquired LDL receptor deficiency, which plays a central role in the genesis of the associated hypercholesterolemia. ${ }^{36}$.

\section{Conclusion}

Predominant lipid abnormalities were reduced HDL and elevated TG levels. Due to the significant association between low HDL levels and risk of incident CKD and CKD progression, Screening of HDL level in CKD patients can be used as a diagnostic tool to detect disease severity. There is statistically significant rise in TG fraction in relation to severity of CKD but prevalence of dyslipidemia in relation to severity of CKD showed no significance

There is minimal increase in serum T.Ch and LDL-Cholesterol level in the study populations.

Lipid abnormalities in chronic kidney disease accelerates the progression of the kidney disease and predisposes to cardio vascular disease risk. Therefore it is worthwhile to detect early and treat dyslipidemia in these patients but a large prospective study is necessary to find the direct 
causal relationship between the lipid abnomality in CKD and cardiovascular disease.

\section{Limitations of the Study}

Smoking, alcoholism may alter the lipid pattern in the body. Their influences in the study group also have to be considered.

$\square$ Patients on drugs affecting lipid metabolism like beta blockers and oral contraceptive pill have to be considered.

We had not estimated the lipid abnormalities in patients who underwent dialysis or renal transplantation.

This is a hospital based study with small study population. Sample size should be more to show the significance of lipid abnormality in relation to CKD severity.

\section{References}

1. Wang H, Naghavi M, Allen C, et al. GBD 2015 Mortality and Causes of Death Collaborators. Global, regional, and national life expectancy, all-cause mortality, and cause-specific mortality for 249 causes of death, 1980-2015: a systematic analysis for the Global Burden of Disease Study 2015. Lancet 2016;388:1459-544.

2. Singh et al.: Epidemiology and risk factors of chronic kidney disease in India - results from the SEEK (Screening and Early Evaluation of Kidney Disease) study. BMC Nephrology 2013 14:114.

3. Vaziri ND: Dyslipidemia of chronic renal Failure the nature, mechanism, and potential consequences. Am J Physiol Renal Physiol 2006; 290: F262-F272.

4. P. Mohanraj, G.Anbazhagan, S. Kalaivalli. "Evaluation of Lipid Profile in Non Diabetic Chronic Kidney Disease Stage 3 and 4". Journal of Evidence Based Medicine and Healthcare; Volume 1, Issue 6, August 2014; Page:338-346.

5. Ganta V et al. Int J Adv.Med 2016 Nov; 3(4) .965-970.
6. Sarnak MJ, Levey AS Schoolwerth AC, Kidney disease as a risk factor for development of cardiovascular disease: a statement from the American Heart Association councils on Kidney in cardiovascular disease, High blood pressure research, Clinical cardiology and Epidemiology and Prevention. Circulation 2003;108:2154-2169.

7. Foley RN, Parfrey PS, Sarnak MJ. Clinical epidemiology of cardiovascular disease in Chronic Renal Disease. Kidney1998; 32: S112-S119.

8. Study of lipid profile and oxidative stress in chronic renal failure. Sumathi M.E., Manjunath M Tembad, Jayaprakashmurthy D.S., Preethi B.P. Biomedical Research 2010;(4): 451-456.

9. Kumari KR and Srinivas B. Study of Lipid Profile in Patients with Chronic Kidney Disease on Conservative Management and Hemodialysis. Int J Sci Stud 2018;6(7):108113.

10. Third Report of the National Cholesterol Education Program(NCEP) Expert Panel on Detection, Evaluation, and Treatment of High Blood Cholesterol in Adults (Adult Treatment Panel III

11. Rajapurkar et al. BMC Nephrology 2012, 13:10.

12. Agarwal SK, Dash SC, IrsadM,Raju S, Pandey RM. Prevalence of chronic renal failure in adults in Delhi.Nephrol Dial Transplant. 2005;20:1638-42.

13. Sathyan et al. Int Jof Community Med Public Health.2016Dec;3(12:3487-3492).

14. Brunskill NJ. Albumin signals the coming of age of proteinuric nephropathy. J Am Soc Nephrol 2004;15: 504-505.

15. Magil AB. Interstitial foam cells and oxidized lipoprotein in human glomerular disease. Mod Pathol 1999; 12: 33-40.

16. Lee HS, Lee JS, Koh HI, and Ko KW. Intra glomerular lipid deposition in routine biopsies. Clin Nephrol,1991; 36: 67-75. 
17. Moorhead JF, Wheeler DC, and Varghese Z. Glomerular structures and lipids in progressive renal disease. Am J Med1989; 87: $12 \mathrm{~N}-20 \mathrm{~N}$.

18. Wheeler DC and Chana RS. Interactions between lipoproteins, glomerular cells and matrix. Miner Electrolyte Metab, 1993; 19: 149-164.

19. Coritsidis G, Rifici V, Gupta S, Rie J, Shan ZH, Neugarten J, and Schlondorff D. Preferential binding of oxidized LDL to rat glomeruli in vivo and cultured mesangial cells in vitro. Kidney Int, 1991; 39: 858866.

20. Gupta S, Rifici V, Crowley S, Brownlee M, Shan Z, and Schlondorff. Interactions of LDL and modified LDL with mesangial cells and matrix. Kidney Int, 1992; 41: 1161-1169.

21. Rovin BH and Tan LC. LDL stimulates mesangial fibronectin production and chemoattractant expression. Kidney Int, 1993;43: 218-225.

22. Hunsicker LG, Adler S, Caggiula A, England BK, Greene T, Kusek JW, Rogers NL, and Teschan PE. Predictors of the progression of renal disease in the Modification of Diet in Renal Disease Study. Kidney Int , 1997;51: 1908-1919.

23. Schaeffner ES, Kurth T, Curhan GC, Glynn RJ, Rexrode KM, Baigent C, Buring JE, and Gaziano JM. Cholesterol and the risk of renal dysfunction in apparently healthy men. J Am Soc Nephrol, 2003;14: 2084-2091.

24. Kuivenhoven JA, Pritchard H, Hill J, Frohlich J, Assmann G, and Kastelein J. The molecular pathology of lecithin: cholesterol acyltransferase (LCAT) deficiency syndrome. J Lipid Res, 1997; 38: 191-205.

25. Gupta DK. Hypedipidemia in patents of chronic renal failure.Bombay Hospital J 1991; 33:45 50.

26. Das BS, Mishra SK, Rao DVP. Serum lipids in chronic renal failure. J Assoc Physicians India 1984; 32:1019 1021.
27. Bagdade J, Casaretto A. Effect of chronic uremia, haemodialysis and renal transplantation on plasma lipids and lipoproteins. J Clin Invest1976;87:374.

28. DIANA M.LEE et al:Lipoprotein particle abnormalities and the impaired lipolysis in renal insufficiency, kidney international, vol.61,2002,pp209-218.

29. Rapport J, Aviram M. "Defective high density lipoprotein composition inpatients on chronic hemodialysis". New Eng J Med, 1978;299: 1326-1329.

30. Nisha I. Parikh, Shih-Jen Hwang, Marin G. Larson,Daniel Levy, Caroline S. Fox. Am J Cardiol:2008:102(1):47-53.

31. Bowel B, Xie Y,Xian H, Balasubramanian S, Al-Aly Z:Low levels of hidh density lipoprotein cholesterol increase the risk of incident kidney disease and its progression.Kidney Int 89:886-896,2016.

32. Shah BV., et al. "Dyslipidemia in patients with chronic renal failure and renal transplant patients". J.Post-grad Med, 1994; 40(2): 52-54.

33. Gerald Appel. "Lipid abnormalities in renal disease". Kidney Int, 1991;39: 169-183.

34. Anderson Sharon, Garcia, Diego L and Brenner B.M., "Renal and systemic manifestations and glomerular disease". Chapter-38 Text book of Kidney, Vol.2, Edn.4, W.B. Saunders Company, Philadelphia, 1991:1852-1860pp.

35. Liang K, Vaziri ND. Gene expression of LDL receptor, HMG-CoA reductase and cholesterol-7 alpha-hydroxylase in chronic renal failure. Nephrol Dial Transplant. 1997; 12: 1381-6

36. Vaziri ND and Liang K. Downregulation of hepatic LDL receptor expression in experimental nephrosis. Kidney Int50: 887893, 1996. 